\title{
Mine and monitor impacts
}

\author{
Modern societies require more and more metals, not least for renewable energy generation. \\ Scientists from a range of disciplines are needed to prospect for ore deposits and provide a basis for \\ sustainable exploration.
}

Our planet's growing population relies on expanding infrastructure and new technologies. Much of this growth is ultimately powered by metals. Supplies in known, easily accessible deposits in Earth's crust are finite. The challenge is to identify new reserves and to make the exploitation of lower-grade deposits worthwhile. Understanding the formation of metallic ore can help locate new exploration targets. At the same time, we need to ensure that future metal extraction and processing is as sustainable as possible. These themes the genesis of metal deposits and concerns around their exploitation - are discussed in a web focus linked to this issue (http://www. nature.com/ngeo/focus/metal-resources/ index.html).

Many of the key metals used in modern technology, such as copper and gold, come from magmas deep within Earth's crust. How these metals migrate to shallower depths in the crust, and concentrate into minable deposits, is unclear. One study in this issue suggests that some metals may essentially float to shallower depths by hitching a ride on the buoyant bubbles that percolate out of the magmas (page 216). Two others propose that chemical reactions between the magmatic vapours and brine fluids ponded in the crust (page 235) or the silicate minerals that make up the crust (page 210) could then trigger the efficient precipitation of metals at shallow depths.

The chemical reactions that trigger ore formation in the modern crust may, in the past, have operated at Earth's surface, suggests work on page 206 of this issue. Over 2.5 billion years ago, a unique combination of conditions - an atmosphere depleted in oxygen, acid rain caused by abundant volcanism and the emergence of simple life forms - might have triggered chemical reactions that induced gold deposition at Earth's surface, forming the Witwatersrand gold deposit in South Africa. The results imply that other Archaean terrains might host gold reserves, too.

Once a viable ore deposit is found, the metals must be extracted - a highly energy-intensive process (O. Vidal et al., Nature Geosci. 6, 894-896; 2013). Large amounts of fossil fuels are consumed to

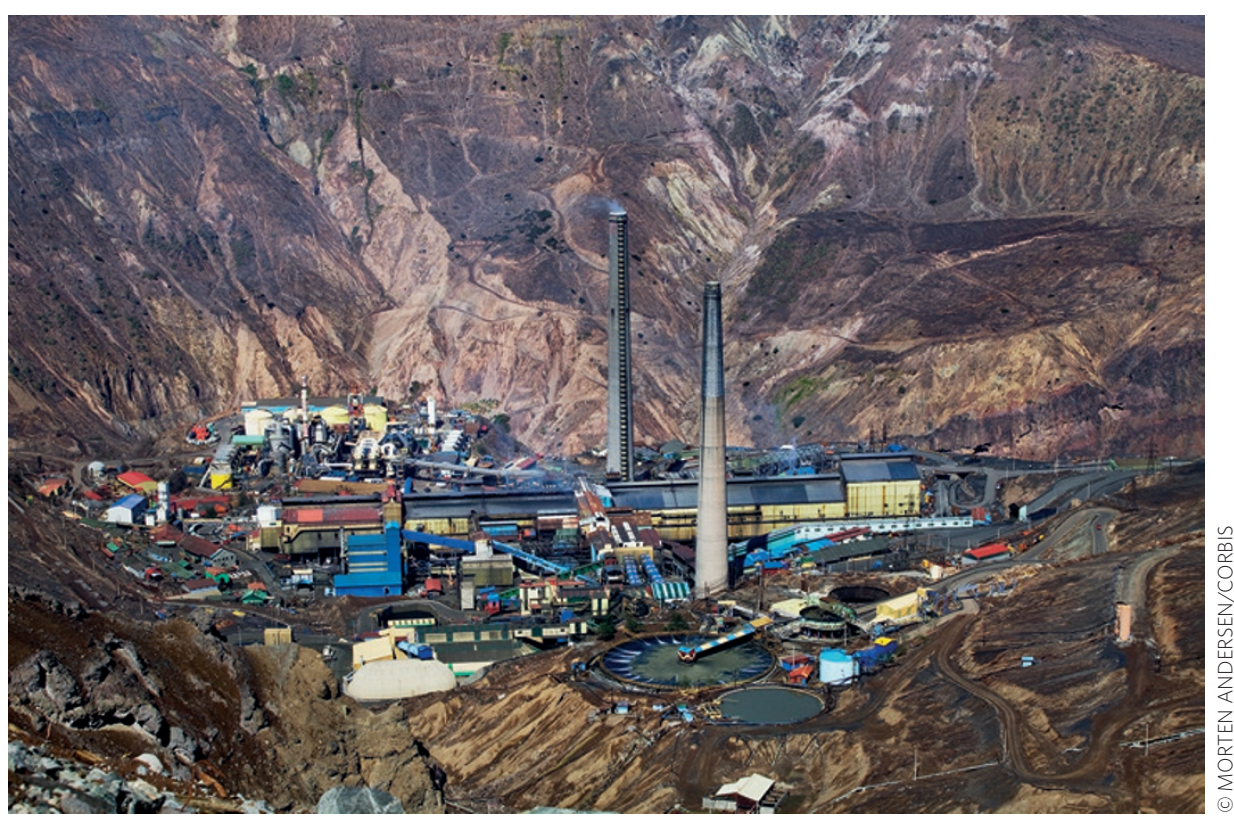

excavate, transport, crush and refine tiny amounts of metals from tonnes of host rock - metals can make up less than $1 \%$ of the rock extracted. Mining has environmental consequences, too, not least the contamination of soil, ground and surface water and a loss of biodiversity. More sustainable methods for metal extraction and processing would be hugely beneficial. One potential technique, biomining (discussed on page 165 of this issue), uses fluids rich with microorganisms to leach metals out of rocks. Currently, this technique is mostly used on waste rock deposits at Earth's surface, but it could potentially be applied to deeply buried ores. This incipient technique will require substantial research and testing by biogeochemists before it can be successfully deployed for deeply buried ore deposits, but it would greatly reduce the need to excavate and crush a tonne of rock for a few kilograms of metal.

Demand is pushing the search for metal and mineral resources into unchartered territories, both on land and in the oceans (M. Schrope, Nature 495, 294; 2013). The sea floors are rich in useful minerals, but, as argued in a Commentary on page 163, expansion of mining into the oceans must be carefully regulated to comprehensively monitor long-term as well as short-term environmental impacts across the full range of affected ecosystems ${ }^{8}$. For this to work, contributions from marine ecologists, oceanographers, as well as lawyers and economists will be essential.

But monitoring environmental impacts is not enough. Sustainable mining practises also need to protect affected communities as exploration spreads around the world. Mines can bring the benefits of jobs, development of infrastructure and trade to remote regions. However the price is often high. Local communities can be displaced from their homes, be exposed to high levels of pollution and experience changing social dynamics. If mining projects proceed in inhabited areas, impacts on local societies must be closely monitored - and social scientists need to be part of the design of sustainable mining strategies.

The need for collaboration between the various sectors of society is beginning to be recognized (http://www.kinglobal. org/catalyst.php). Successful sustainable mining will rely on projects that facilitate dialogue between mining companies, physical and social scientists, charities and local communities. 